\title{
Multiple human papillomavirus infections among Chinese women with and without cervical abnormalities: a population-based multi-center cross-sectional study
}

\author{
Ni Li ${ }^{1}$, Lin Yang ${ }^{1 \dagger}$, Kai Zhang ${ }^{1}$, Yawei Zhang ${ }^{2}$, Tongzhang Zheng ${ }^{2}$ and Min Dai ${ }^{\text {* }}$ \\ ' National Office for Cancer Prevention and Control, Cancer Institute and Hospital, Chinese Academy of Medical Sciences, Peking Union Medical College, \\ Beijing, China \\ ${ }^{2}$ School of Public Health, Yale University, New Haven, CT, USA
}

\section{Edited by:}

Karina Braga Ribeiro, Fundação Antonio Prudente Hospital A. C. Camargo, Brazil

\section{Reviewed by:}

Rajesh Dikshit, Tata Memorial Center, India

José Eduardo Levi, Instituto de Medicina Tropical da Universidade de São Paulo, Brazil

\section{${ }^{*}$ Correspondence:}

Min Dai, National Office for Cancer Prevention and Control, Cancer Institute and Hospital, Chinese Academy of Medical Sciences, No. 17 Panjiayuannanli, Chaoyang District, Beijing 100021, China.

e-mail:daimin/yon@gmail.com

${ }^{+}$Lin Yang has contributed equally to this work.
Background: Despite an increase in the number of studies conducted in recent years on human papillomavirus (HPV) and cervical cancer epidemiology, the profile of multiple HPV infections remain obscure, particularly among Chinese women. During 2004-2005, a series of population-based HPV prevalence surveys were performed by Cancer Institute and Hospital of Chinese Academy of Medical Sciences (CIHCAMS) and International Agency for Research on Cancer (IARC). Based on these surveys, we evaluated the prevalence and risk factors of multiple HPV infections, and explored its association with cervical abnormalities among Chinese women. Methods: A total of 2374 women from three study centers underwent gynecological examinations with valid cytology and their HPV results were included in the analysis. Forty-four HPV types were detected using the GP5+/6+ PCR-based enzyme immunoassay. An unconditional logistic regression model was used to evaluate the effect of multiple HPV infections on cervical lesions and its risk factors adjusting for confounders. The between-groups difference was evaluated by a heterogeneity test based on the $Q$ test. Results: One hundred and eleven women of multiple HPV infections was found among 2374 Chinese women with a prevalence of $5.28 \% 195 \%$ $\mathrm{Cl}=3.86-5.60 \%)$, which attributed to $28.98 \%(95 \% \mathrm{Cl}=24.49-33.81 \%)$ of all of the 383 HPV-positive women. A significantly increased risk of multiple HPV infections was found in the older women ( $\geq 45$ years; adjusted $\mathrm{OR}=1.52,95 \% \mathrm{Cl}=1.02-2.27$ ) and those having more than three sexual partners (adjusted $\mathrm{OR}=2.10,95 \% \mathrm{Cl}=1.05-4.17$ ) after adjustment for age-group, study area, and number of sexual partner. We also found that the risk of high-grade lesions was significantly higher than that of low-grade lesions with the multiple HPV infections ( $P_{\text {heterogeneity }}=0.044$ ), but not as significantly with the single HPV infection $\left(P_{\text {heterogeneity }}=0.108\right.$ ). Conclusion: Multiple HPV Infections, especially with highrisk HPV types, may be a substantial indicator either for public cervical cancer prevention or clinical implications.

Keywords: human papillomavirus, multiple infections, cervical lesion, Chinese, epidemiology

\section{INTRODUCTION}

Epidemiological and laboratory-based studies have identified that infection of high-risk human papillomavirus (HPV) as a necessary but not sufficient cause of cervical cancer (Munoz, 2000). More than $100 \mathrm{HPV}$ genotypes have been fully characterized on the basis of the isolation of complete genomes present (IARC Working Group on the Evaluation of Carcinogenic Risks to Humans, 2007). With the general improvement in HPV DNA testing method, overall HPV prevalence in cervical cancer increased significantly from $85.9 \%$ in studies published from 1990 to 1999 to $92.9 \%$ in studies published from 2006 to 2009, and the increases were large for the prevalence of multiple HPV infections (from 4.0 to $14.4 \%$; Li et al., 2011). Therefore, more and more evidences showed that the occurrence of multiple infections is frequent as opposed to occasional.
Due to the geographic variation of overall HPV prevalence, occurrence also varied worldwide with a range of $0.4 \%$ in Spain to $8.3 \%$ in Nigeria for multiple infections in cytologically normal women (Clifford et al., 2005) and 4\% in North America to $19 \%$ in Africa in cervical cancer cases, respectively (de et al., 2010). However, the reports focusing on the prevalence of multiple infections of HPV among Chinese women and its risk factors were rare. Moreover, the association between multiple HPV infections and cervical lesions remain unclear.

Therefore, we re-analyzed the data from three populationbased cross-sectional HPV prevalence surveys among Chinese women performed in 2004-2005 to evaluate the prevalence and its risk factors of multiple HPV infections, and explore the link between the concurrent infection with multiple HPV types and the cervical abnormalities in the certain population in the present study. 


\section{MATERIALS AND METHODS STUDY SUBJECTS}

Between 2004 and 2005, the Cancer Institute and Hospital, Chinese Academy of Medical Sciences (CIHCAMS) and International Agency for Research on Cancer (IARC) collaborated and performed three population-based HPV prevalence surveys among women in rural and urban areas of China, namely Yangcheng County, Shanxi Province (Dai et al., 2006), Shenzhen City, Guangdong Province (Wu et al., 2007), and Shenyang City, Liaoning Province (Li et al., 2006), respectively. Of these three study centers, Yangcheng County is a rural area of China, and the other two centers are urban areas of China.

Details of the surveys have been reported previously. Briefly, women aged 15-59 years without pregnancies and hysterectomies were enumerated. All participants signed an informed consent form recommended by IARC and CIHCAMS ethical review committees, which approved these three studies.

\section{STUDY PROCEDURES}

Study procedures were identical for these three study centers ( $\mathrm{Li}$ et al., 2009). To summarize, a standardized questionnaire interview was administered to all participants by trained interviewers in separated rooms to increase the compliance. Then the participants provided a sample of exfoliated cervical cell for liquid-based cytology (LBC) and HPV testing and then underwent a clinical examination including testing of visual inspection with acetic acid (VIA), visual inspection with Lugol's Iodine solution (VILI), and digital colposcopy.

\section{LABORATORY TEST}

Liquid-based cytology was performed at CIHCAMS, Beijing, China and the results were classified according to the Bethesda System (Solomon et al., 2002). All abnormal smears, as well as $10 \%$ of normal smears chosen at random were reviewed by a second experienced cytologist. HPV detection was performed in the Department of Pathology at the Vrije University Medical Center, Amsterdam, the Netherlands, using a GP5+/6+ PCR-based enzyme immunoassay. Genotyping of $44 \mathrm{HPV}$ types [HPV6, 11, $16,18,26,30,31,32,33,34,35,39,40,42,43,44,45,51,52$, $53,54,55,56,57,58,59,61,64,66,67,68,69,70,71$ (equivalent to CP8061), 72, 73, 81 (equivalent to CP8304), 82 (IS39 and MM4 subtypes), 83 (equivalent to MM7), 84 (equivalent to MM8), cand85, 86, cand89 (equivalent to CP6108), and JC9710] was performed by reverse line blot hybridization of PCR products (van den Brule et al., 2002), and HPV types were classified, for some analyses, into high- and low-risk types (Munoz et al., 2003).

\section{BIOPSIES TAKEN AND CERVICAL LESIONS ASSESSMENT}

Cervical biopsies were prepared and read by a pathologist at CIHCAMS, Beijing, China and the histological diagnosis were made by two pathologists. Women with suspected abnormalities found through VIA, VILI, or colposcopy had a colposcopy-directed biopsy-taken and women whose entire squamocolumnar junction could not be visualized underwent endocervical curettage (ECC). In total, 515 women were take biopsies directly. Meanwhile, 54 women were underwent ECC with 28 cases of CIN1 or worse histologically diagnosed.
When LBC results became available, all women with cytologically abnormal lesions (atypical squamous cells of undetermined significance, ASCUS or worse) not detected by VIA, VILI, or digital colposcopy were recalled and had biopsies taken (Li et al., 2009). Finally, 64.08\% (91/142) women who should be called back visited doctors again for biopsy-taken and 62 cases of CIN1 or worse were histologically diagnosed.

Hence, in this study, cervical abnormalities were defined as lowgrade lesions (including the presence of histologically confirmed cervical intraepithelial neoplasia 1 and cytologically confirmed low-grade lesion if histological results absent) or high-grade lesions (including the presence of histologically confirmed cervical intraepithelial neoplasia 2 or worse and the cytologically confirmed high-grade lesion or worse if histological results absent). On account of the performance of multiple screening tests and the high proportion of histological confirmation, women with negative diagnoses of all screening tests were considered as true negative subjects. After combining the histological and cytological diagnosis results together, 109 (4.59\%) and 66 (2.78\%) cases of low- and high-grade lesions were diagnosed, respectively.

\section{STATISTICAL ANALYSIS}

The prevalence of multiple HPV infections and its corresponding $95 \%$ confidence interval (CI) were calculated. Pearson chi-square test was used to evaluate the difference between multiple HPV prevalence across studies. The statistical significance of trends for multiple HPV prevalence among different cervical lesions was assessed by a non-parametric test, which was an extension of the Wilcoxon rank-sum test. Odds ratios (ORs) and its corresponding 95\% CI were used to evaluate the risk of cervical lesions with multiple HPV infections and its risk factors (including social-demographic characteristics, reproductive and menstrual factors, sexual behaviors, etc.) by means of an unconditional logistic regression model. A heterogeneity test was used to examine the between-groups difference based on the $\chi^{2}$-based $Q$ test and the heterogeneity was considered significant if $P<0.05$. All analyses were performed using the Stata statistical software (version 11.0, StataCorp, College Station, TX, USA).

\section{RESULTS}

A total of 3504 women (941 from Yangcheng County, 1563 from Shenzhen City, and 1000 from Shenyang City) participated in the HPV prevalence surveys, among which 2374 women (662 from Yangcheng County, 1027 from Shenzhen City, and 685 from Shenyang City) underwent gynecological examinations with valid cytology and their HPV results were included in the analysis.

The mean age of the 2374 women was $38.50 \pm 10.38$ years, varying between $35.19 \pm 9.09$ years in Shenzhen City and $41.16 \pm 10.43$ years in Shenyang City. The overall prevalence of HPV infection ranged from $14.80 \%(95 \% \mathrm{CI}=12.18-17.74 \%)$ in Yangcheng County to $16.79 \%$ (95\% CI $=14.06-19.80 \%)$ in Shenyang City (Figure 1). One hundred and eleven women with multiple HPV infections were found among all the participants. The prevalence of multiple HPV infections was $4.68 \%$ (95\% CI $=3.86-5.60 \%)$ with the highest prevalence in Shenyang City $(5.26 \%, 95 \% \mathrm{CI}=3.71-7.21 \%)$, followed by Yangcheng County $(4.54 \%, 95 \% \mathrm{CI}=3.08-6.41 \%)$, and Shenzhen City 
(4.38\%, 95\% CI $=3.21-5.82 \%$ ), respectively (Figure 1). There was no significant difference in HPV prevalence among these three centers either for HPV infection of any type $\left(\chi^{2}=1.22\right.$, $P=0.544)$ or multiple types $\left(\chi^{2}=0.74, P=0.689\right)$. Therefore, we merged the data from these three centers for the further analyses.

One hundred and eleven women with multiple HPV infections attributed to $28.98 \%$ of all of the $383 \mathrm{HPV}$-positive women, among which 100 (90.09\%) were infected with at least one high-risk type. Most common patterns of multiple infections were concurrent infections with two types, which accounted for $74.77 \%(83 / 111)$ of all subjects with multiple HPV infections. With the increase of age, there was no significant increase of number of multiple HPV infections ( $P$ for trend $=0.524$, data not shown). However, though there was also no significant trend in the increase of number of multiple HPV infections with the deterioration of cervical lesions ( $P$ for trend $=0.927$, data not shown), the prevalence of multiple HPV infections increased with the severity of cervical lesions $\left(\chi^{2}=360.06, P<0.001 ;\right.$ Table 1$)$.

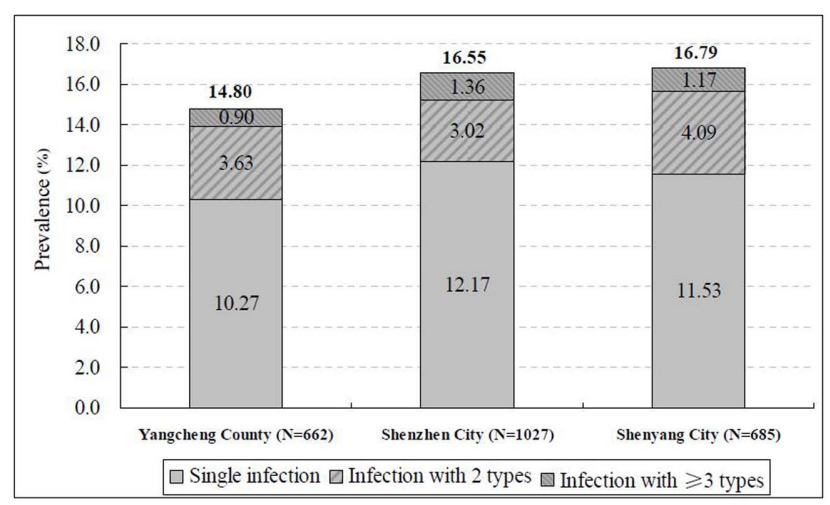

FIGURE 1 | Prevalence of HPV infections among 2374 women, by study center.
To further interpret the link between multiple HPV infections and cervical lesions, we did a comparison of the association strength between the risk of cervical lesions and single and multiple infections. The rate of single and multiple infections by cervical lesions were calculated by the formula of single or multiple HPVpositive number divided by the HPV negative number in case of the confoundings between single and multiple HPV infections (Table 2). It was certain that with the increase of severity of cervical lesions, the prevalence of any HPV type increased. Compared to women with normal cervixes, women with lowgrade cervical lesions, as well as women with high-grade lesions, had a significantly higher prevalence of both single $(\mathrm{OR}=9.65$, $95 \% \mathrm{CI}=6.26-14.87$ and $\mathrm{OR}=26.90,95 \% \mathrm{CI}=13.27-54.51$ for low- and high-grade lesions, respectively) and multiple infections $(\mathrm{OR}=9.40,95 \% \mathrm{CI}=5.08-17.39$ and $\mathrm{OR}=62.76,95 \%$ $\mathrm{CI}=29.70-132.62$ for low- and high-grade lesions, respectively). More interestingly, we also found that the OR values in the subgroups of high-grade lesions were significantly higher than that in the subgroups of low-grade lesions for multiple HPV infections $\left(P_{\text {heterogeneity }}=0.044\right)$, but not significantly for single HPV infection $\left(P_{\text {heterogeneity }}=0.108\right.$; Table 2$)$.

To explore the implications of individual HPV types in multiple infections, we analyzed the prevalence of single and multiple infections with the individual HPV types in cervical lesions. Generally, HPV16 was by far the most common type with a multiple prevalence of $1.39 \%$ (95\% CI $=0.96-1.95 \%)$, followed by HPV $58(1.10 \%, 95 \% \mathrm{CI}=0.72-1.60 \%)$ and HPV52 (0.84\%, 95\% $\mathrm{CI}=0.52-1.30 \%$ ), respectively (Table 3 ). After being stratified by cervical lesions, we found that the prevalence ratio (PR) between multiple and single infection was less than 1.00 for three HPV types among women with cervical lesions (low-grade lesion or worse), and, in the increasing order, were 0.52 for HPV16 and 0.90 for both HPV31 and HPV33. All the remaining HPV types were more frequently found as a part of a multiple infection than a single infection in the subgroup of cervical lesions presence with the $\mathrm{PR}$ over than 1.00. As the representative of low-risk HPV types,

Table 1 | Occurrence of multiple infections of HPV by age-group, study area, and cervical lesion.

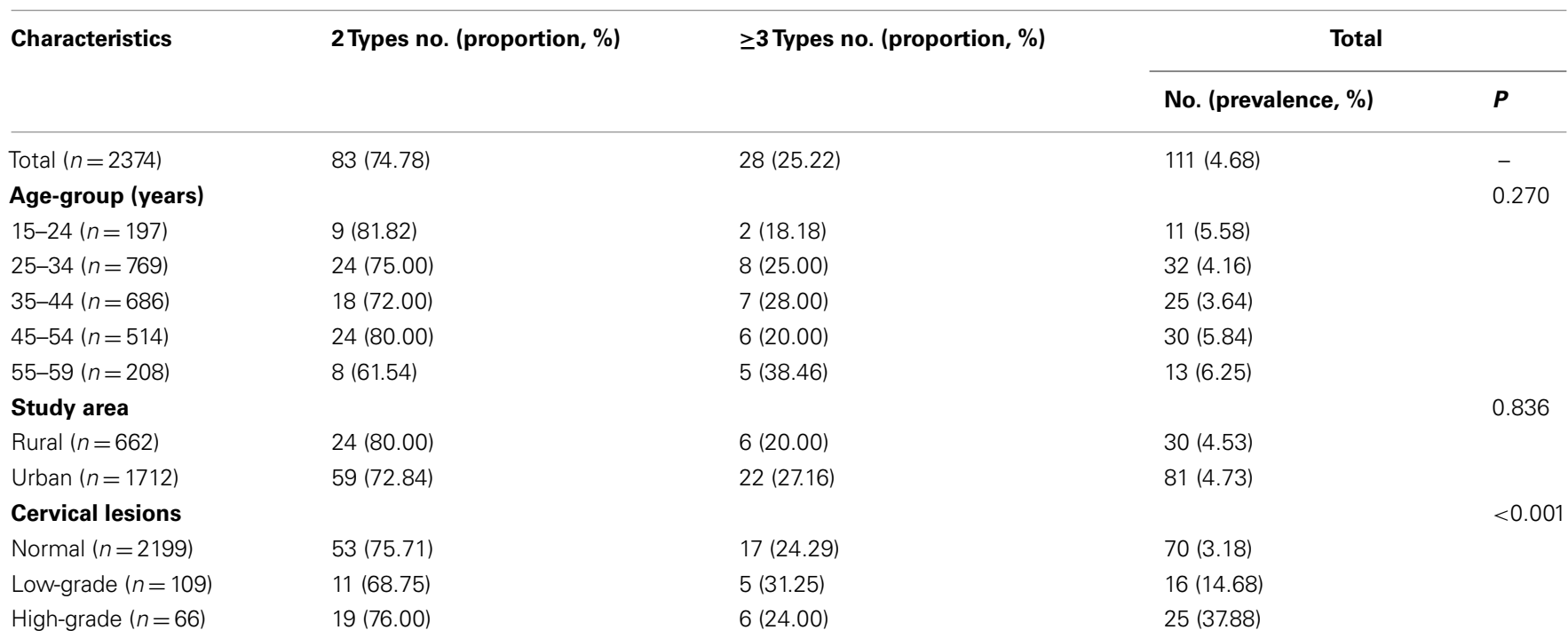


Table 2 | Prevalence of single and multiple infections of HPV in cervical lesions.

\begin{tabular}{|c|c|c|c|c|c|c|c|c|c|}
\hline \multirow{2}{*}{$\begin{array}{l}\text { Lesion } \\
\text { grade }\end{array}$} & \multicolumn{3}{|c|}{ Any-type infection } & \multicolumn{3}{|c|}{ Single infection } & \multicolumn{3}{|c|}{ Multiple infection } \\
\hline & $\begin{array}{l}\%\left(n+{ }^{d} /\right. \\
\left.n-{ }^{e}\right)\end{array}$ & $\mathrm{OR}^{\mathrm{a}}(95 \% \mathrm{Cl})$ & $P_{\text {heterogeneity }}{ }^{\mathrm{c}}$ & $\begin{array}{l}\%(n+d) \\
\left.n-{ }^{e}\right)\end{array}$ & OR $(95 \% \mathrm{Cl})$ & $\boldsymbol{P}_{\text {heterogeneity }}$ & $\begin{array}{l}\%\left(n+{ }^{d} /\right. \\
\left.n-^{e}\right)\end{array}$ & OR (95\% Cl) & $\boldsymbol{P}_{\text {heterogeneity }}$ \\
\hline Normal & $\begin{array}{l}12.1 \\
(266 / 1933)\end{array}$ & Ref. $^{\dagger}$ & & $\begin{array}{l}9.21 \\
(196 / 1933)\end{array}$ & Ref. & & $\begin{array}{l}3.49 \\
(70 / 1933)\end{array}$ & Ref. & \\
\hline $\begin{array}{l}\text { High- } \\
\text { grade }\end{array}$ & $\begin{array}{l}83.33 \\
(55 / 11)\end{array}$ & $\begin{array}{l}36.33 \\
(18.78-70.29)\end{array}$ & 0.044 & $\begin{array}{l}73.17 \\
(30 / 11)\end{array}$ & $\begin{array}{l}26.90 \\
(13.27-54.51)\end{array}$ & 0.108 & $\begin{array}{l}69.44 \\
(25 / 11)\end{array}$ & $\begin{array}{l}62.76 \\
(29.70-132.62)\end{array}$ & 0.044 \\
\hline
\end{tabular}

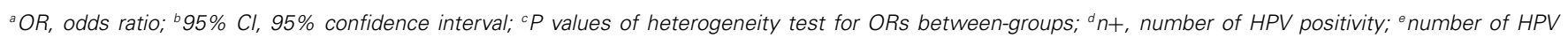
negativity; ${ }^{f}$ Ref., reference group.

HPV6 and 11 were absent from single infection among women with cervical lesions (Table 3).

For the analysis of risk factors of multiple HPV infection, we found that women older than 45 years $(\mathrm{OR}=1.49,95 \% \mathrm{CI}=1.01-$ 2.22) and have had more than three sexual partners $(\mathrm{OR}=2.11$, 95\% CI $=1.06-4.19$ ) were associated with multiple HPV infections using a binary logistic regression. Results from multivariable models also confirmed that women older than 45 years (adjusted $\mathrm{OR}=1.52,95 \% \mathrm{CI}=1.02-2.27)$ and have had more than three sexual partners (adjusted $\mathrm{OR}=2.10,95 \% \mathrm{CI}=1.05-4.17$ ) were significantly associated with multiple HPV infections after adjustment for age-groups ( $<45$ and $\geq 45$ years), study areas (rural and urban), and number of sexual partners $(1,2$, and $\geq 3$ sexual partners; Table 4). In addition, we also revealed that with the increase of number of sexual partners, the prevalence of multiple HPV infections significantly increased ( $P$ for trend $=0.047$; data not shown).

\section{DISCUSSION}

Since HPV prevalence varies across the geographic regions, it is reasonable to postulate that the prevalence of multiple HPV infections is also heterogenic in different geographic regions. Based on a series of population-based HPV prevalence surveys performed by IARC all over the world with a standardized protocol, it is easy and reliable for us to compare the multiple HPV infections among different geographic areas. In this population-based multi-center cross-sectional study, we found that the prevalence of multiple HPV infections among cytologically normal women in China $(3.18,95 \% \mathrm{CI}=2.49-4.00 \%)$ was higher than that in the other countries in Asia and Europe but lower than that in South America and Sub-Saharan Africa (Clifford et al., 2005). But the proportion (28.98\% in our study) of the multiple HPV infections among all HPV-positive Chinese women was similar to other report (Mendez et al., 2005). The results revealed that the co-infection with at least two types were frequent among Chinese women other than occasional. We also found that there was no association between number of HPV types and the presence of cervical abnormalities, which was consistent with the results of a cohort study performed in rural Costa Rica (Herrero et al., 2000). The results suggested that the risk of cervical lesions may be more associated with the combination of HPV subtypes as opposed to the number of types. We also found that the prevalence of single HPV infection was higher than that of multiple HPV infections in women with cervical lesions for HPV16, 31, and 33. In addition, the single infection with low-risk HPV types was absent and the prevalence of multiple infections with low-risk HPV types was also very low in the women with cervical abnormalities, which may suggest a stronger carcinogenesis for Alpha-9 Species of HPV among the certain population, especially for HPV16, 31, and 33.

Age and sexual behavior were shown as the major risk factors of multiple HPV infections among the certain population. In contrast to studies in some other areas, such as Denmark (Mejlhede et al., 2009), older age was considered as a risk factor to multiple infections in Chinese women. We should note that, differing from the other areas with the peak of HPV prevalence in younger women, China showed a flat age-specific prevalence curve of any HPV type (Franceschi et al., 2006). It implied a great possibility of the low rate of the clearance of HPV infection in Chinese women compared to women in Europe and North America. Therefore, due to the decrease of the immunity, the increase of multiple HPV infection in older women was understandable. As we have known, the most common mode of transmission of anogenital HPV is by sexual activity. Many studies proved the association between sexual behaviors and HPV prevalence. However, the relationship between sexual behaviors and multiple HPV infections remains unclear. Our study showed that multiple sexual partners was another risk factor of multiple HPV infection, and with the increase of number of sexual partners, the prevalence of multiple HPV infection increased $(P$ for trend $=0.047$ ). Considering the low exposure to multiple sexual partners $(5.67 \%, 95 \% \mathrm{CI}=4.00$ $7.76 \%$ for $\geq 3$ sexual partners) and the higher rate of multiple HPV infection $(6.77 \%, 95 \% \mathrm{CI}=4.94-9.01 \%)$ among the older Chinese women, we may postulate that the occurrence of multiple HPV infections among Chinese women is probably mainly due to the accumulation of infections other than co-occurrence at one time. Hence, the great probability of persistent infection among Chinese women can explain the high incidence of cervical cancer in China to an extent.

More interestingly, we observed that though multiple HPV infection increased the risk of both low- and high-grade cervical lesions, the risk of high-grade lesions was increased 


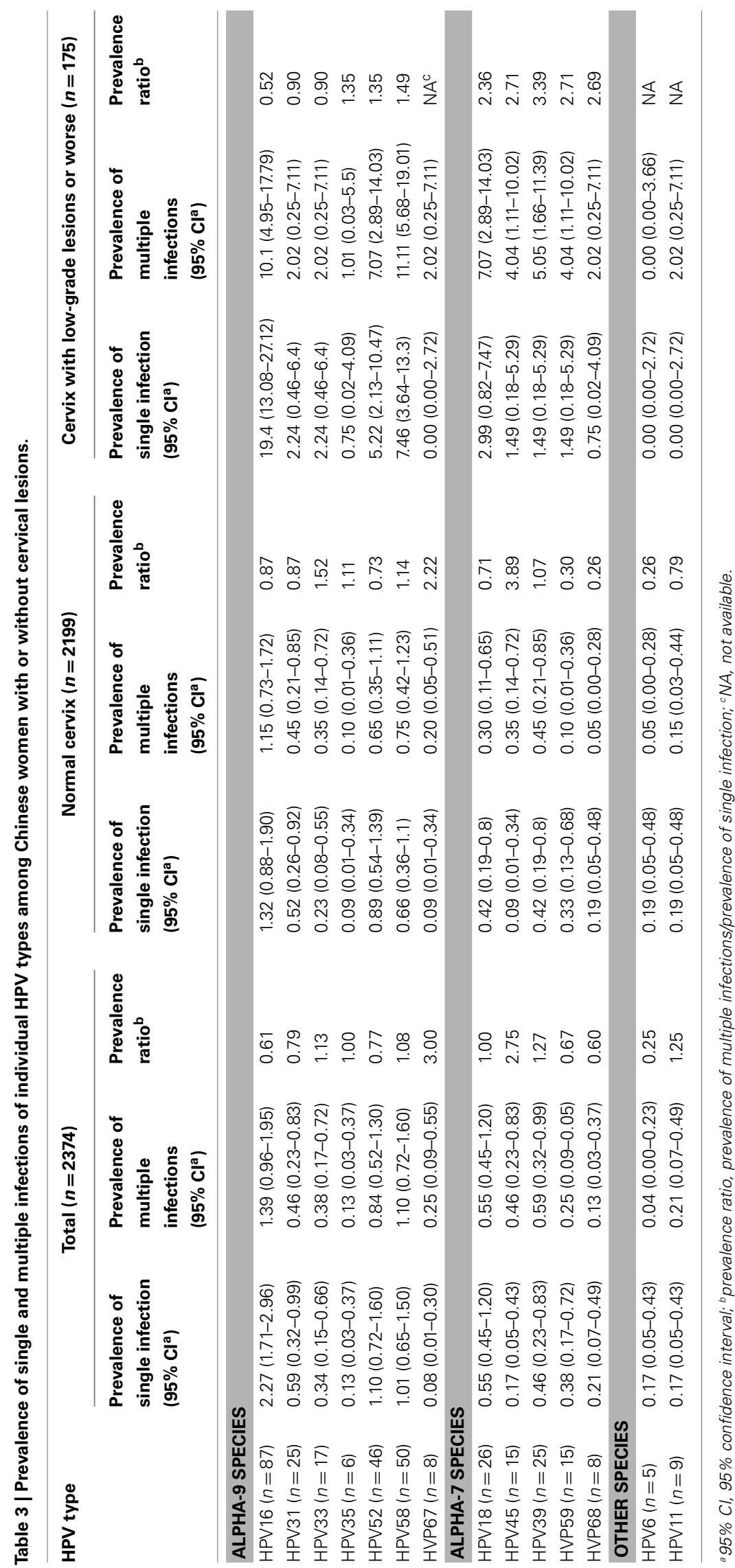


Table 4 | Characteristics related to multiple HPV infections among 2374 Chinese women.

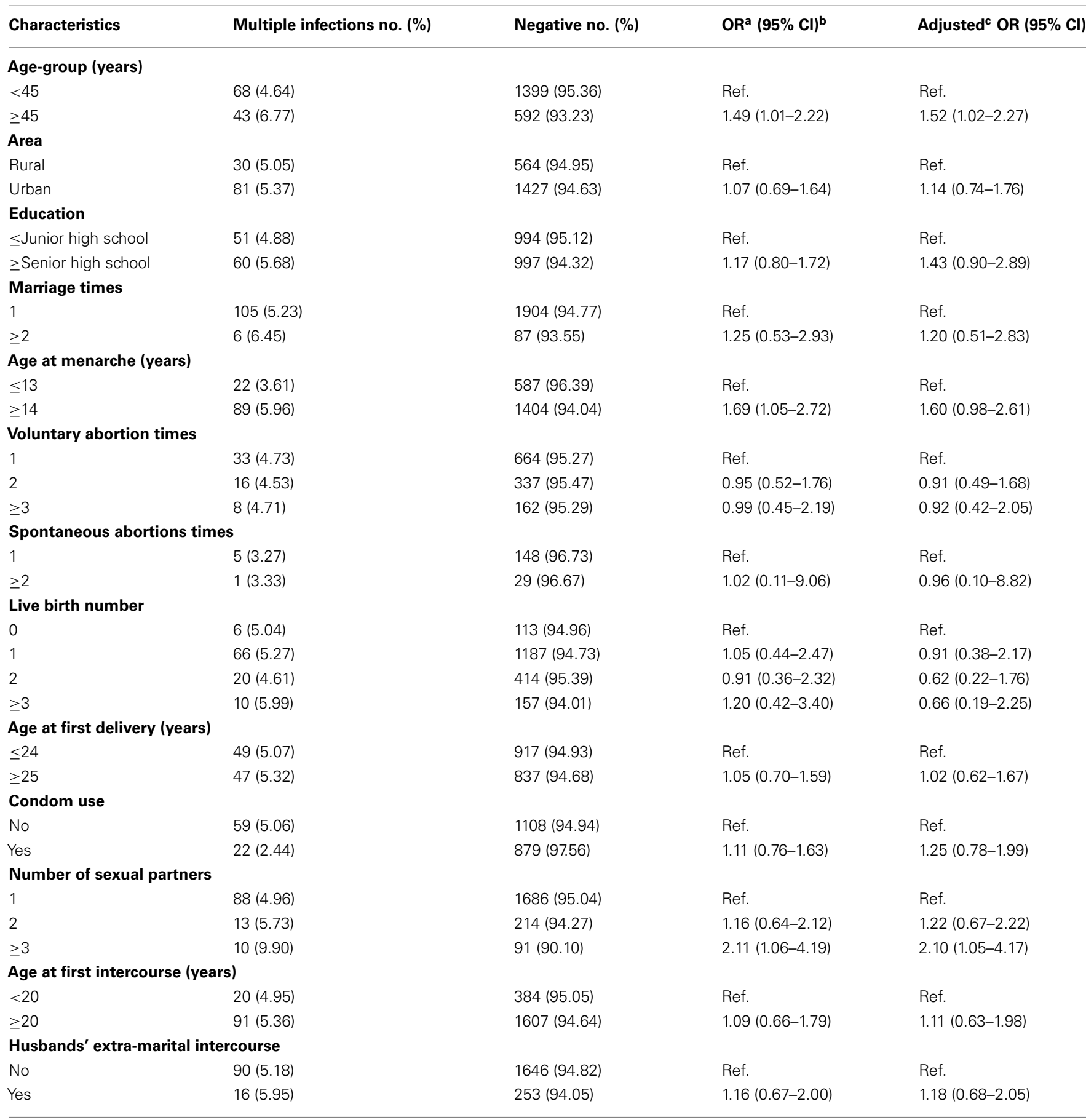

${ }^{a}$ OR, odds ratio; ${ }^{b} 95 \% \mathrm{Cl}, 95 \%$ confidence interval; ' ${ }^{a}$ adjusted for age-groups, study areas, and number of sexual partners.

more significantly than low-grade lesions $\left(P_{\text {heterogeneity }}=0.044\right)$. But the pattern did not show for single HPV infection $\left(P_{\text {heterogeneity }}=0.108\right)$. The results implied that multiple HPV infections could be used as a substantial indicator to identify the high-risk population in Chinese women either for public prevention or clinical implication (Spinillo et al., 2009).

The main limitation of the study is the relatively small sample size, especially in stratified analyses. On the other hand, the cross-sectional study design was less efficient in demonstrating the mechanism and natural history of multiple HPV infections among Chinese women clearly. The multi-center large scale cohort studies on the natural history of HPV infection will be very helpful in the near future. However, as we know, it's the first time the profile of multiple HPV infections among Chinese women was provided. The use of a standardized protocol and methodology in these three study centers made the comparison and data combination 
reasonable and believable. From a practical viewpoint, the studies described the prevalence of multiple HPV infection among women with or without cervical lesions, and its risk factors. The findings of our study provide the basic and scientific data for the introduction of vaccinations in China in the future.

\section{ACKNOWLEDGMENTS}

We gratefully thank Dr. Silvia Franceschi and Gary M. Clifford from International Agency for Research on Cancer, who designed the population-based cross-sectional study and greatly supported our study, and Dr. Youlin Qiao and his team from the Department

\section{REFERENCES}

Clifford, G. M., Gallus, S., Herrero, R., Munoz, N., Snijders, P. J., Vaccarella, S., Anh, P. T., Ferreccio, C., Hieu, N. T., Matos, E., Molano, M., Rajkumar, R., Ronco, G., de Sanjosé, S., Shin, H. R., Sukvirach, S., Thomas, J. O., Tunsakul, S., Meijer, C. J., Franceschi, S., and IARC HPV Prevalence Surveys Study Group. (2005). Worldwide distribution of human papillomavirus types in cytologically normal women in the International Agency for Research on Cancer HPV prevalence surveys: a pooled analysis. Lancet 366 , 991-998.

Dai, M., Bao, Y. P., Li, N., Clifford, G. M., Vaccarella, S., Snijders PJ Huang, R. D., Sun, L. X., Meijer, C. J., Qiao, Y. L., and Franceschi, S. (2006). Human papillomavirus infection in Shanxi Province, People's Republic of China: a populationbased study. Br. J. Cancer 95, 96-101.

de, S. S., Quint, W. G., Alemany, L., Geraets, D. T., Klaustermeier, J. E., Lloveras, B., Tous, S., Felix, A., Bravo, L. E., Shin, H. R., Vallejos, C. S., de Ruiz, P. A., Lima, M. A., Guimera, N., Clavero, O., Alejo, M., LlombartBosch, A., Cheng-Yang, C., Tatti, S. A., Kasamatsu, E., Iljazovic, E., Odida, M., Prado, R., Seoud, M., Grce, M., Usubutun, A., Jain, A., Suarez, G. A., Lombardi, L. E., Banjo, A., Menéndez, C., Domingo, E. J., Velasco, J., Nessa, A., Chichareon, S. C., Qiao, Y. L., Lerma, E., Garland, S. M., Sasagawa, T., Ferrera, A., Hammouda, D., Mariani, L., Pelayo, A., Steiner, I., Oliva, E., Meijer, C. J., Al-Jassar, W. F., Cruz, E., Wright, T. C., Puras, A., Llave, C. L., Tzardi, M., Agorastos, T., Garcia-Barriola, V., Clavel, C., Ordi, J., Andújar, M., Castellsagué, X., Sánchez, G. I., Nowakowski, A. M., Bornstein, J., Muñoz, N., Bosch, F. X., and Retrospective International Survey and HPV Time Trends Study Group. (2010). Human papillomavirus genotype attribution in invasive cervical cancer: a retrospective cross-sectional worldwide study. Lancet Oncol. 11, 1048-1056.

Franceschi, S., Herrero, R., Clifford, G. M., Snijders, P. J., Arslan, A., Anh, P. T., Bosch, F. X., Ferreccio, C., Hieu, N. T., Lazcano-Ponce, E., Matos, E., Molano, M., Qiao, Y. L., Rajkumar, R., Ronco, G., de Sanjosé, S., Shin, H. R., Sukvirach, S., Thomas, J. O., Meijer, C. J., and Muñoz, N. (2006). Variations in the age-specific curves of human papillomavirus prevalence in women worldwide. Int. J. Cancer 119, 2677-2684.

Herrero, R., Hildesheim, A., Bratti, C., Sherman, M. E., Hutchinson, M., Morales J Balmaceda, I., Greenberg, M. D., Alfaro, M., Burk, R. D., Wacholder, S., Plummer, M., and Schiffman, M. (2000). Populationbased study of human papillomavirus infection and cervical neoplasia in rural Costa Rica. J. Natl. Cancer Inst. 92, 464-474.

IARC Working Group on the Evaluation of Carcinogenic Risks to Humans. (2007). Human papillomaviruses. IARC Monogr. Eval. Carcinog. Risks Hum. 90, 1-636.

Li, L. K., Dai, M., Clifford, G. M., Yao, W. Q., Arslan, A., Li N Shi, J. F., Snijders, P. J., Meijer, C. J., Qiao, Y. L., and Franceschi, S. (2006). Human papillomavirus infection in Shenyang City, People's Republic of China: a population-based study. $\mathrm{Br}$. J. Cancer 95, 1593-1597.

Li, N., Franceschi, S., Howell-Jones, R., Snijders, P. J., and Clifford, G. M. (2011). Human papillomavirus type distribution in 30,848 invasive cervical cancers worldwide: variation by geographical region, histological type and year of publication. Int. J. Cancer 128, 927-935.

Li, N., Shi, J. F., Franceschi, S., Zhang, W. H., Dai, M., Liu B Zhang, Y. Z., Li, L. K., Wu, R. F., De Vuyst, H., Plummer, M., Qiao, Y. L., and Clifford, G. (2009). Different cervical cancer screening approaches in a Chinese multicentre study. Br. J. Cancer 100, 532-537.

of Epidemiology, Cancer Institute and Hospital, Chinese Academy of Medical Sciences, who managed the field work.

Sources of support: This work was supported by Take-home grant from the National Natural Science Fund from the National Natural Science Foundation of China (Grant No. 30901236 and 81172757), Research Fund for the Doctoral Program of Higher Education in China from Chinese Ministry of Education (Grant No. 20091106120030), Return Grant from International Agency for Research on Cancer (CRA No. FEL/09/02), and Fogarty Training Grant from the National Institute of Health (NIH; Grant No. 1D43TW008323-01).

Mejlhede, N., Bonde, J., and Fomsgaard, A. (2009). High frequency of multiple HPV types in cervical specimens from Danish women. APMIS 117, 108-114.

Mendez, F., Munoz, N., Posso, H., Molano, M., Moreno, V., van den Brule, A. J., Ronderos, M., Meijer, C., Munoz, A., and Instituto Nacional de Cancerologia Human Papillomavirus Study Group. (2005). Cervical coinfection with human papillomavirus (HPV) types and possible implications for the prevention of cervical cancer by HPV vaccines. J. Infect. Dis. 192, 1158-1165.

Munoz, N. (2000). Human papillomavirus and cancer: the epidemiological evidence. J. Clin. Virol. 19, $1-5$.

Munoz, N., Bosch, F. X., de, S. S., Herrero, R., Castellsague, X., Shah, K. V. Snijders, P. J., Meijer, C. J., and International Agency for Research on Cancer Multicenter Cervical Cancer Study Group. (2003). Epidemiologic classification of human papillomavirus types associated with cervical cancer. N. Engl. J. Med. 348, 518-527.

Solomon, D., Davey, D., Kurman, R., Moriarty, A., O’Connor, D., Prey, M. Raab, S., Sherman, M., Wilbur, D., Wright, T. Jr., Young, N., Forum Group Members, and Bethesda 2001 Workshop. (2002). The 2001 Bethesda System: terminology for reporting results of cervical cytology. JAMA 287, 2114-2119.

Spinillo, A., Dal, B. B., Gardella, B., Roccio, M., Dacco', M. D., and Silini, E. M. (2009). Multiple human papillomavirus infection and high grade cervical intraepithelial neoplasia among women with cytological diagnosis of atypical squamous cells of undetermined significance or low grade squamous intraepithelial lesions. Gynecol. Oncol. 113, 115-119.

van den Brule, A. J., Pol, R., FransenDaalmeijer, N., Schouls, L. M., Meijer, C. J., and Snijders, P. J. (2002).
GP5+/6+ PCR followed by reverse line blot analysis enables rapid and high-throughput identification of human papillomavirus genotypes. $J$. Clin. Microbiol. 40, 779-787.

Wu, R. F., Dai, M., Qiao, Y. L., Clifford, G. M., Liu, Z. H., Arslan, A., Li, N., Shi, J. F., Snijders, P. J., Meijer, C. J., and Franceschi, S. (2007). Human papillomavirus infection in women in Shenzhen City, People's Republic of China, a population typical of recent Chinese urbanisation. Int. J. Cancer 121, 1306-1311.

Conflict of Interest Statement: This manuscript has not been submitted to any other journals for publication or presented in any meeting. All authors have made substantial contributions to the conception and design of the study, acquisition of data, analysis and interpretation of data, drafting of the article, revising it critically for important intellectual content, and gave final approvals of the version submitted. There are no commercial associations that might pose a conflict of interest with the submitted article.

Received: 02 August 2011; accepted: 30 September 2011; published online: 18 October 2011.

Citation: Li N, Yang L, Zhang K, Zhang $Y$, Zheng $T$ and Dai $M$ (2011) Multiple human papillomavirus infections among Chinese women with and without cervical abnormalities: a population-based multi-center crosssectional study. Front. Oncol. 1:38. doi: 10.3389/fonc. 2011.00038

This article was submitted to Frontiers in Cancer Epidemiology and Prevention, a specialty of Frontiers in Oncology. Copyright (C) 2011 Li, Yang, Zhang, Zhang, Zheng and Dai. This is an openaccess article subject to a non-exclusive license between the authors and Frontiers Media SA, which permits use, distribution and reproduction in other forums, provided the original authors and source are credited and other Frontiers conditions are complied with. 